\title{
A Study of Field-Ring Design using a Variety of Analysis Method in Insulated Gate Bipolar Transistor (IGBT)
}

\author{
Eun Sik Jung*, Sin-su Kyoung* Hunsuk Chung* and Ey Goo Kang ${ }^{\dagger}$
}

\begin{abstract}
Power semiconductor devices have been the major backbone for high-power electronic devices. One of important parameters in view of power semiconductor devices often characterize with a high breakdown voltage. Therefore, many efforts have been made, since the development of the Insulated Gate Bipolar Transistor (IGBT), toward having higher level of breakdown voltage, whereby the typical design thereof is focused on the structure using the field ring. In this study, in an attempt to make up more optimized field-ring structure, the characteristics of the field ring were investigated with the use of theoretical arithmetic model and methodologically the design of experiments (DOE). In addition, the IGBT having the field-ring structure was designed via simulation based on the finding from the above, the result of which was also analyzed. Lastly, the current study described the trench field-ring structure taking advantages of trench-etching process having the improved field-ring structure, not as simple as the conventional one. As a result of the simulation, it was found that the improved trench field-ring structure leads to more desirable voltage divider than relying on the conventional field-ring structure.
\end{abstract}

Keywords: IGBT, DOE, Field-ring, Trench field-ring structure

\section{Introduction}

For a power semiconductor device, usually widely used as a switch or rectifier in power supply applications, one of its particularly important requirements relates to the characteristic of breakdown voltage to endure high voltage. As devices in such applications evolve, a great deal of efforts has been paid to boast the breakdown voltage. The fruit of such efforts is an IGBT, gradually gaining wider applications for modern devices and appliances due to its various advantages. The IGBT is an element combining advantages of MOSFET (Metal-Oxide-Semiconductor Field Effect Transistor) structure as well as advantages of BJT (Bipolar Junction Transistor) structure. Combined with fast switching characteristic of the MOSFET along with high-current and low-saturation-voltage capability of the BJT, the IGBT expands its scope of applications such as display, automobile, motor and household appliances [1]. Breakdown voltage under the high voltage environment is a key characteristic required in the IGBT, which is therefore designed by implementing an edge-termination structure - called edge termination region - in the lateral side of its junction so as to alleviate the electric field in the junction edge [2-6]. Fig. 1 shows the basic structure of edge termination. In contrast with the existing MOSFET having a lateral channel design so that gate, source and drain terminal are placed linearly, the power MOSFET has

$\dagger$ Corresponding Author: Department of Photovoltaic Engineering, Far East University, Korea. (keg@kdu.ac.kr)

* Department of Electrical Engineering, Korea University, Korea. (odin11@korea.ac.kr)

Received: October 4, 2013; Accepted: July 5, 2014

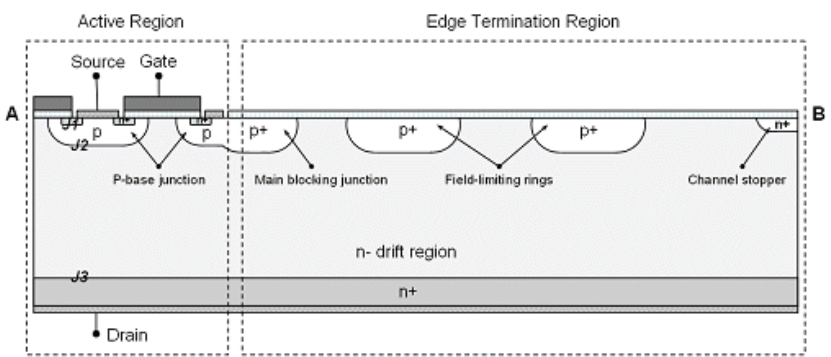

Fig. 1. The IGBT structure adding the edge termination region

a vertical layout in which a drain terminal is placed in a vertically lower position. The active region in the entire power MOSFET structure is part in which channel that controls current flow is created, occupying the most area of an element. The edge termination region plays a role of improving the breakdown voltage characteristic in the outskirt part of an element including the field-ring structure analyzed in this study [7-10].

The current study proposed an interpretive model to analyze the field-ring characteristics, and described various methods for designing the field-ring structure and the trenched field limiting ring structure using trench etching technique.

\section{Structure \& Operating Characteristics of Field-ring}

Fig. 2 is a schematic diagram showing the depletion 


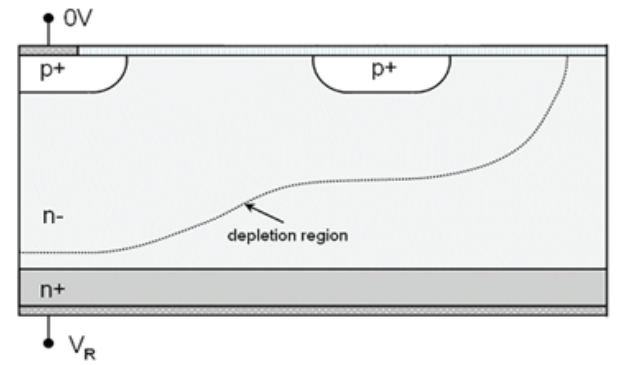

Fig. 2. The IGBT structure showing the depletion region that has one field-ring when reverse voltage is induced

region in only one field ring when the reverse voltage is supplied in the basic power MOSFET structure. If the field-ring structure is not implemented, the depletion layer (region) is formed only in the main junction, thus causing the electric field to be more intense there. If the field-ring structure is added as shown in Fig. 2, however, it serves to reduce the amount of the field crowding at the main junction by spreading the depletion layer past consecutively lower potential floating junctions. A junction becomes biased when the spreading depletion layer punches through to the floating junction. These independent junctions act to increase the depletion layer spreading, thereby decreasing the high electric field at the main junction. As such, the field ring structure plays a role of a sort of voltage divider.

\section{Descriptive Modeling of the Field-ring Characteristics}

Figs. 3(a) and (b) show two different schematics depending on existence of the field-ring structure. In Fig. $3(\mathrm{a}), \mathrm{V}_{\mathrm{M} 0}$ is defined as voltage in the main junction, namely indicating the difference of potential between the main junction and the cathode. Therefore, by defining $V_{R}$ as reverse voltage, $\mathrm{V}_{\mathrm{M} 0}$ is represented as;

$$
V_{R}=V_{M 0}
$$

In a same manner, $V_{M}$ of Fig. 3(b) is defined as voltage in the main junction, that is the difference of potential between the main junction and the field-ring, and $\mathrm{V}_{\mathrm{F}}$ is defined as voltage in the field-ring, that is, the difference of potential between the field-ring and the cathode.

$$
V_{R}=V_{M}+V_{F}
$$

To calculate $\mathrm{V}_{\mathrm{M} 0}, \mathrm{~V}_{\mathrm{M}}$ and $\mathrm{V}_{\mathrm{F}}$, the Poisson's equation in the cylindrical coordinates must be used $[14,15]$.

$$
\frac{1}{r} \frac{d r E}{d r}=\frac{q N_{d}}{\varepsilon_{s i}}
$$

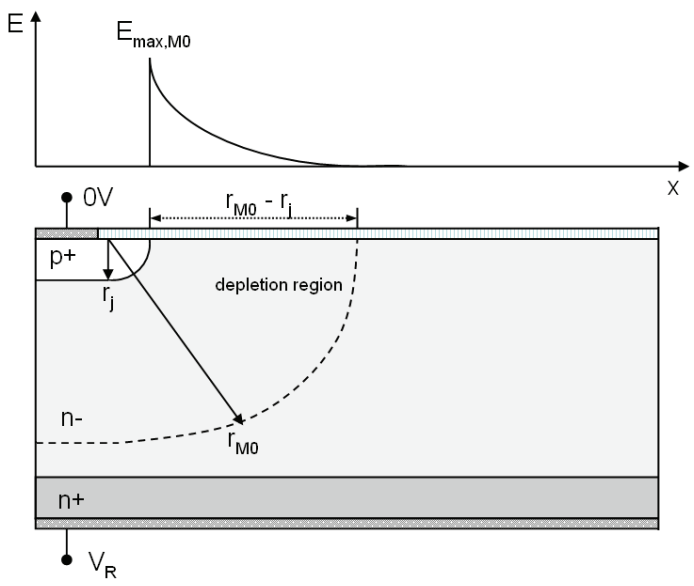

(a) Schematic showing the depletion in the basic main junction.

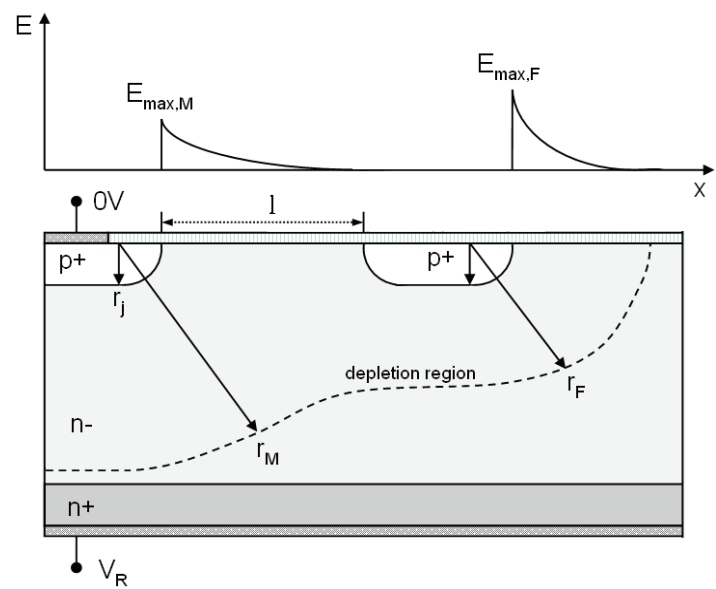

(b) Schematic showing the depletion region in the fieldring implemented structure

Fig. 3. Schematic showing the depletion region

To obtain the generalized expression of the electric field, first of all, integral is required by using the boundary condition in which the electric field of the depletion region boundary in Eq. (3) is zero (0).

$$
E=-\frac{q N_{d}}{2 \varepsilon_{s i}}\left(\frac{r_{M 0}^{2}-r^{2}}{r}\right)
$$

When two terms of Eq. (4) are integrated using the boundary condition in which the electric field of the main junction is 0 , the generalized voltage expression can be obtained as follows;

$$
V=-\frac{q N_{d}}{2 \varepsilon_{s i}}\left(\frac{r_{j}^{2}-r^{2}}{2}+r_{M 0}^{2} \ln \frac{r}{r_{j}}\right)
$$

Since the voltage in Eq. (5) is not $0 \mathrm{~V}$, but based on the voltage in cathode, the equation can be expressed as; 


$$
\begin{gathered}
E(r)=\frac{q N_{d}}{2 \varepsilon_{s i}}\left(\frac{r^{2}{ }_{M 0}-r^{2}}{r}\right) \\
V(r)=\frac{q N_{d}}{2 \varepsilon_{s i}}\left(\frac{r^{2}{ }_{j}-r^{2}}{2}+r_{M 0}^{2} \ln \frac{r}{r_{j}}\right)
\end{gathered}
$$

Since in Fig. 3(b) the depletion layer edge is $\left(r=r_{M 0}\right)$, the following can be obtained by using Eq. (7).

$$
\begin{aligned}
V_{R} & =V\left(r_{M 0}\right) \\
& =\frac{q N_{d}}{2 \varepsilon_{s i}}\left(\frac{r^{2}{ }_{j}-r_{M 0}^{2}}{2}+r^{2}{ }_{M 0} \ln \frac{r_{M 0}}{r_{j}}\right)
\end{aligned}
$$

Voltage $\left(\mathrm{V}_{\mathrm{M}}\right)$ of the main junction can be represented as the difference of potential between two junctions.

$$
\begin{aligned}
V_{M} & =V\left(r_{j}+l\right)-V\left(r_{j}\right) \\
& =\frac{q N_{d}}{2 \varepsilon_{s i}}\left(\frac{r^{2}{ }_{j}-\left(r_{j}+l\right)^{2}}{2}+r_{M}^{2} \ln \frac{\left(r_{j}+l\right)}{r_{j}}\right)
\end{aligned}
$$

Therefore, the field ring voltage $\left(\mathrm{V}_{\mathrm{F}}\right)$ can be determined as follows by using Eqs. (2), (8) and (9).

$$
V_{F}=\frac{q N_{d}}{2 \varepsilon_{s i}}\left(\frac{-r_{M 0}^{2}+\left(r_{j}+l\right)^{2}}{2}+r_{M}^{2} \ln \frac{r_{M 0}}{\left(r_{j}+l\right)}\right)
$$

The field ring junction associated with field ring voltage $\left(V_{F}\right)$ can serve as a voltage divider only when the distance of main junction and ring junction is less than the punch-through distance $\left(\mathrm{r}_{\mathrm{M} 0}-\mathrm{r}_{\mathrm{j}}\right)$.

$$
\begin{gathered}
E_{\max , M}=\frac{q N_{d}}{2 \varepsilon_{s i}}\left(\frac{r_{M 0}^{2}-r_{j}^{2}}{r_{j}}-\frac{r_{F}^{2}-\left(r_{j}+l\right)^{2}}{r_{j}+l}\right) \\
E_{\max , F}=\frac{q N_{d}}{2 \varepsilon_{s i}}\left(\frac{r_{F}^{2}-r_{j}^{2}}{r_{j}}\right)
\end{gathered}
$$

In consequence, the optimal location of the filed ring junction can be calculated under the condition that both $\mathrm{E}_{\mathrm{Max}, \mathrm{M}}$ and $\mathrm{E}_{\mathrm{Max}, \mathrm{F}}$ have the same value. In the above equation, $\varepsilon_{s i}$ is the permittivity of silicon, $N_{d}$ is background impurity concentration, $r_{j}$ is the junction depth, and $\mathrm{r}_{\mathrm{M} 0}$ is the thickness of depletion region.

\section{Field-ring design}

\subsection{Design through theoretical mathematical modeling}

The core advantage obtainable by way of implementing the field-ring structure to the existing power MOSFETs is to reduce the amount of the field crowding at the main junction edge part. Despite that, processing is required for the optimal design by calculating and specifying the distance between main junction and field-ring junction, rather than the simple employment of the field-ring structure. In this sense, as mentioned above, the optimal positioning is achieved at the time when values of $\mathrm{E}_{\mathrm{Max}, \mathrm{M}}$ and $\mathrm{E}_{\mathrm{Max}, \mathrm{F}}$ in Fig. 3(b) have the same value.

In the case of $200 \mathrm{~V}$ IGBT, background impurity concentration $\left(\mathrm{N}_{\mathrm{d}}\right)$ is $1 \times 10^{14} \mathrm{~cm}^{-3}$ and junction $\operatorname{depth}\left(\mathrm{r}_{\mathrm{j}}\right)$ is $10 \mu \mathrm{m}$, the calculation between the main junction and the ring junction is made as shown in Fig. 4.

As can be seen in Fig. 4, it is found that, when $200 \mathrm{~V}$ of reverse voltage is induced, values of $\mathrm{E}_{\mathrm{Max}, \mathrm{M}}$ and $\mathrm{E}_{\mathrm{Max}, \mathrm{F}}$ vary with distances between the main junction and the ring junction. Based on Eqs. (11) and (12), we can see that the value $E_{\mathrm{Max}, \mathrm{M}}$ is less than the value $E_{\mathrm{Max}, \mathrm{F}}$ when the distance between the two junctions is shorter than the cross point (plotted at $5.7 \mu \mathrm{m}$ ), while showing the opposite result when the distance between the two is longer than the reference point (A). Consequently, we come to know that the optimal point coincides with A point, which means that the difference between $\mathrm{E}_{\mathrm{Max}, \mathrm{M}}$ value and $\mathrm{E}_{\mathrm{Max}, \mathrm{F}}$ value is $5.7 \mu \mathrm{m}$.

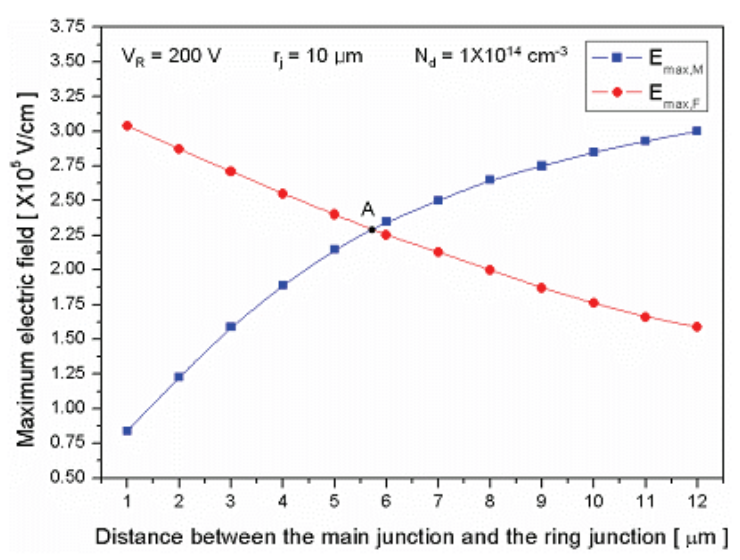

Fig. 4. Variations of $E_{M a x, M}$ value and $E_{M a x, F}$ value depending on distances between the main junction and the ring junction

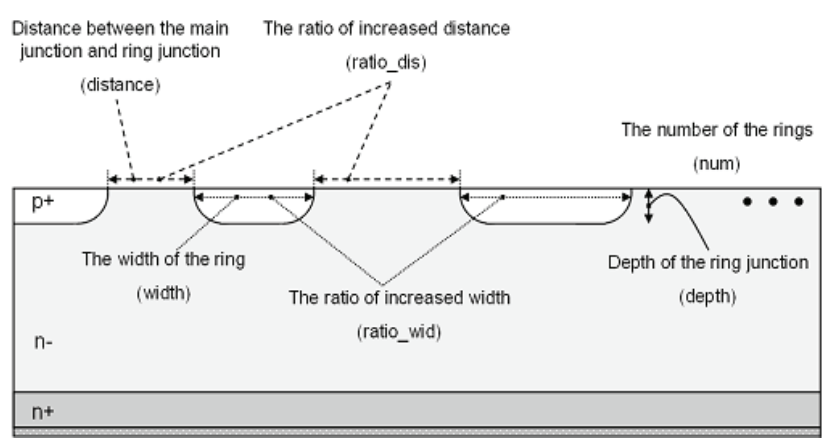

Fig. 5. Six variables to be used in designing the field ring with the use of the DOE 


\subsection{Design through Design of Experiment (DOE)}

The DOE indicates the methodological experiment where the number of variables and their cope of variation are in advance fixed in order to understand interactions of many variables influential to the breakdown voltage of the field-ring structure. As shown in Fig. 5, many considerations have to be taken in designing the field-ring structure, including number of ring structures, distance between the main junction and the first ring structure, distance between rings, concentration of ring, width of ring, whether the interval between rings varies or not, whether or not change exists in width of ring, and lastly the distance from the ring to the end of the element. As hinted in the above, the most difficult drawback in designing the field ring is that there are so many parameters that have effect on the optimized design. Under the situation like that, the DOE serves as a good alternative, making it possible to recognize individualistic or interactive impacts amongst a variety of variables, eventually enabling us to represent the breakdown voltage as functions in terms of specific variables. In this context, testing hereof requires inadvance determination of the scope and level of variations with respect to many parameters concerned.

\subsubsection{Experimental design}

To incorporate the field-ring to an element, this study designed the NPT planar type of IGBT in which the breakdown voltage of the main active area is around $1,800 \mathrm{~V}$.

As outlined in Table 1, the concentration of $\mathrm{N}$ - drift region was set to $6 \times 10^{13} \mathrm{~cm}^{-3}$ and thickness to $220 \mu \mathrm{m}$ to obtain the breakdown voltage no less than $1800 \mathrm{~V}$. Table 2 shows 6 parameters that determine the characteristics of the field-ring as emphasized before; more specifically, distance between main junction and first ring (Distance), total number of rings (Num), ring-to-ring distance changing ratio (Ratio_dis), bonding depth of ring (Depth), width of ring (Width), and ring width changing ratio (Ratio_wid). Table 2 also shows the upper and lower limits of variation as per each parameter. Extracting the result based on the DOE was made by using TSUPREM and

Table 1. Doping profile of IGBT

\begin{tabular}{c|c}
\hline \multicolumn{2}{c}{ Design Parameter } \\
\hline $\mathrm{N}+$ Emitter $\left(\mathrm{cm}^{-2}\right)$ & $2 \times 10^{19}$ \\
\hline $\mathrm{P}+$ Anti latch-up $\left(\mathrm{cm}^{-2}\right)$ & $1 \times 10^{19}$ \\
\hline P base $\left(\mathrm{cm}^{-2}\right)$ & $1 \times 10^{17}$ \\
\hline $\mathrm{N}$ - Drift region $\left(\mathrm{cm}^{-2}\right)$ & $6 \times 10^{13}$ \\
\hline P + Collector $\left(\mathrm{cm}^{-2}\right)$ & $5 \times 10^{17}$ \\
\hline
\end{tabular}

Table 2. Six parameters having effect on breakdown voltage

\begin{tabular}{c|c|c|c|c|c|c}
\hline & Distance & Num & Ratio_dis & Depth & Width & Ratio_wid \\
\hline Low & $1.5(\mu \mathrm{m})$ & 2 & 1 & $1.3(\mu \mathrm{m})$ & $5(\mu \mathrm{m})$ & 1 \\
\hline High & $3.0(\mu \mathrm{m})$ & 5 & 1.2 & $2.3(\mu \mathrm{m})$ & $10(\mu \mathrm{m})$ & 1.2 \\
\hline
\end{tabular}

MEDICI simulation.

\subsubsection{Experimental result and analysis}

Fig. 6 shows the result on breakdown voltage relying on 6 parameters in such a way that, at the time of one parameter varying, other 5 parameters remain at fixed values. This figure shows the variation of High and Low as presented in Table 2. In this figure, it is found that the greater the slop of each line, the more contributed to the variation of breakdown voltage. We can see that the greatest variation is found in total number of rings (Num), followed by width of ring (Width) as the second and distance between main junction and first ring (Distance) as the third. In other words, if a parameter makes the field ring to occupy more region, the parameter has been more contributed to their increase of breakdown voltage.

In addition to the independent variation of each parameter, however, considerations should be taken on interactions of 6 parameters. Fig. 7 presents intuitive insight on how the effect of one parameter differs with the level variation of other parameters. The finding that the degree of one parameter influential to breakdown voltage differs with the variation of another parameter means that interactions between these two parameters exist, which is bigger with more different slopes in two reactions. It is found from the graph that greater interactions occur in

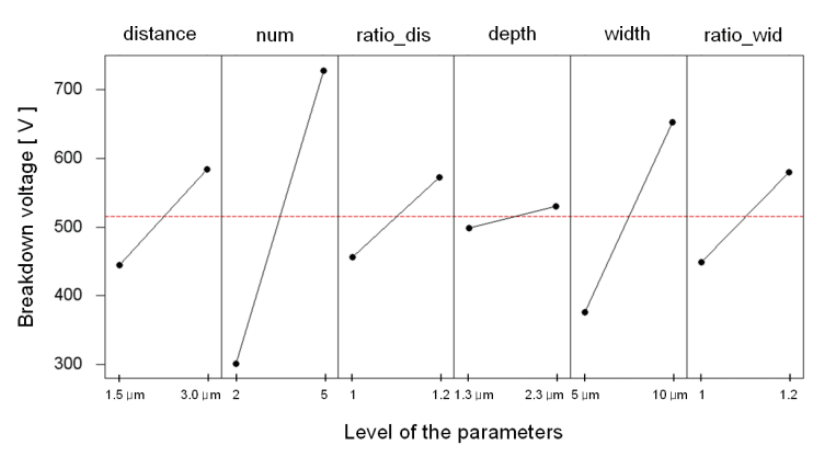

Fig. 6. Each parameter having effect on breakdown voltage

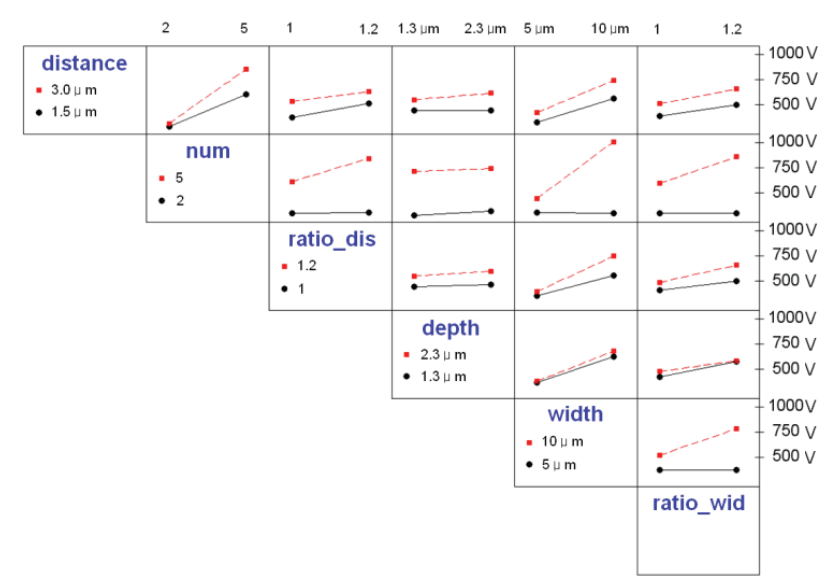

Fig. 7. Interaction plot of parameters having effect on breakdown voltage 


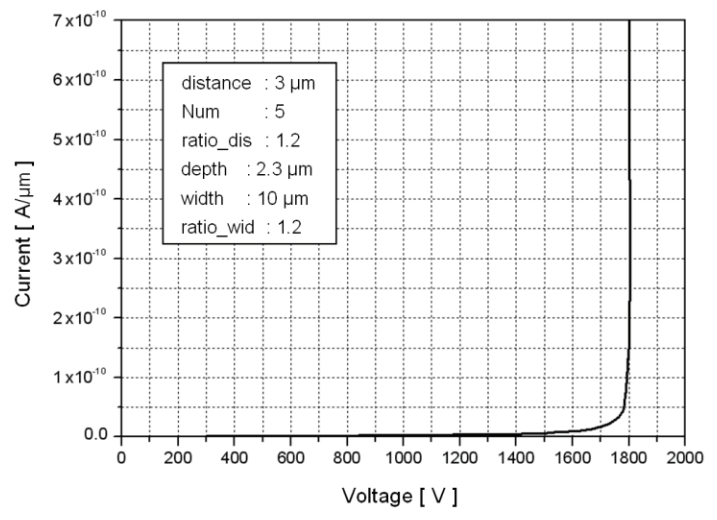

Fig. 8. Breakdown Voltage of $1800 \mathrm{~V}$ class of the field-ring based on the DOE

order of total number of rings (Num), width of ring (Width) and ring-to-ring distance changing ratio (Ratio_dis), where the increase rate of breakdown voltage is particularly high with increasing Num. To generalize the above, the most influential parameters in designing the field-ring can be summarized by total number of rings (Num), width of ring (Width) and ring-to-ring distance changing ratio (Ratio_dis). Since all of these 3 parameters act to directly increase the area of the field-ring, it can be known that the contradictory relationship exists between the area efficiency and the characteristics of the breakdown voltage.

Taking advantage of the simulation result based on the DOE and the analysis result thereof, the breakdown voltage can be modeled as a function of 6 parameters, which is given by;

$$
\begin{aligned}
& B V[V] \approx 514+213(\text { num })+143(\text { num })(\text { width }) \\
& +138(\text { width })+69(\text { dist })+67(\text { num })(\text { ratio_wid }) \\
& +65(\text { width })(\text { ratio_wid })
\end{aligned}
$$

In reality, an attempt was made to design $1,800 \mathrm{~V}$ class of IGBT that has the field-ring structure by using Eq. 13. According to Eq. 13, the prerequisites to have $1800 \mathrm{~V}$ or greater breakdown voltage are; firstly, the number of rings must be 5; secondly, the depth of junction must be at least $2.3 \mu \mathrm{m}$, thirdly, the distance between the main junction and the ring must gradually increase, starting from $3 \mu \mathrm{m}$; and lastly, the width of field-ring must be $10 \mu \mathrm{m}$ or greater.

Fig. 8 shows the graph of actual voltage and current plotted with respect to those parameters, where it can be known that the breakdown voltage takes place around $1803 \mathrm{~V}$.

\section{Trench Field-ring Structure}

\subsection{Correlation between junction depth and breakdown voltage}

Junction depth acts as a very important parameter

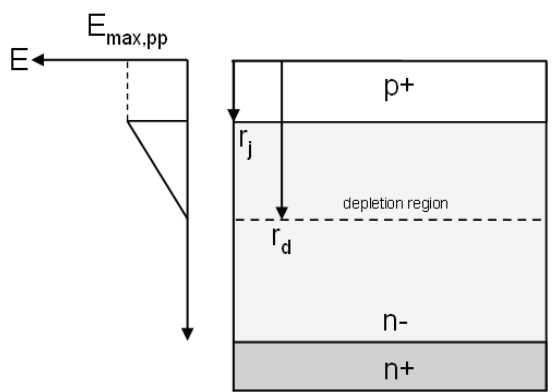

(a) Cross-section of planar junction and change of electric field depending on distance

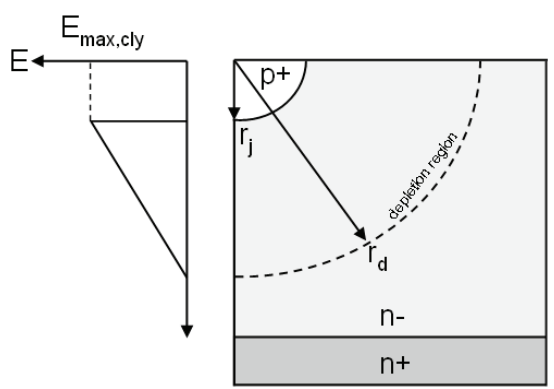

(b) Cross-section of cylindrical junction and change of electric field depending on distance

Fig. 9. Cross-section of planar and cylindrical junctions and change of electric field depending on distance

influential to the characteristics of the breakdown voltage. Since the deeper the depth of junction is, the greater the curvature of junction edge, thus alleviating crowding of the electric field, breakdown voltage increase [19].

To look into the variations in the characteristics of breakdown voltage depending on depth of junction, planar junction and cylindrical junction are depicted in Fig. 9.

In Fig. 9(a), to calculate the max electric field of the planar junction, $\mathrm{E}_{\mathrm{Max}, \mathrm{PP}}$, the Poisson equation can be interpreted as;

$$
\frac{d E}{d x}=\frac{q N_{d}}{\varepsilon_{s i}}
$$

If both terms are integrated by using the boundary condition that the electric field of depletion layer boundary $\left(\mathrm{r}=\mathrm{r}_{\mathrm{d}}\right)$ is 0 , we have;

$$
E(r)=\frac{q N_{d}}{\varepsilon_{s i}}\left(r+r_{d}\right)
$$

Since the max electric field of planar junction, $E_{\mathrm{Max}, \mathrm{PP}}$, occurs at $\left(r=r_{j}\right)$, it can be represented as;

$$
E_{\max , p p}=E\left(r_{j}\right)=\frac{q N_{d}}{\varepsilon_{s i}}\left(r_{d}\right)
$$

For the next, to calculate the max electric field of the 
cylindrical junction, $\mathrm{E}_{\mathrm{Max}, \mathrm{cyl}}$, in Fig. 9(b), the Poisson equation in the cylindrical coordinate can be interpreted as;

$$
\frac{1}{r} \frac{d r E}{d}=\frac{q N_{d}}{\varepsilon_{s i}}
$$

If both terms are integrated by using the boundary condition that the electric field of depletion layer boundary $\left(\mathrm{r}=\mathrm{r}_{\mathrm{d}}\right)$ is 0 , then;

$$
E(r)=-\frac{q N_{d}}{2 \varepsilon_{s i}}\left(\frac{r_{d}^{2}-r^{2}}{r}\right)
$$

Since the max electric field of cylindrical junction, $E_{\text {Max,cyl }}$, occurs at $\left(r=r_{j}\right)$, it can be represented as;

$$
E_{\max , c y l}=E\left(r_{j}\right)=-\frac{q N_{d}}{2 \varepsilon_{s i}}\left(\frac{r_{d}^{2}-r_{j}^{2}}{r_{j}}\right)
$$

As the concentration of the substrate has a very low value in view of IGBT characteristics, it can be assumed that width of the depletion layer, $r_{d}$, is very big than depth of junction, $r_{j}$. Therefore, Eq. 16 via approximation can be expressed as;

$$
E_{\max , c y l} \approx-\frac{q N_{d}}{2 \varepsilon_{s i}} \frac{r_{d}^{2}}{r_{j}}
$$

If the ratio of Eqs. 16 and Eq.20 is calculated,

$$
\frac{\left|E_{\max , c y l}\right|}{\left|E_{\max , p p}\right|} \approx \frac{r_{d}}{2 r_{j}}
$$

Eq. 21 shows that the max electric field of the junction edge can be determinable depending on depth of junction, $r_{j}$; if the depth of junction is 2 times deeper, the max electric field of the junction edge will be decreased by a 0.5 times. Since the coefficient associated with the breakdown phenomenon is a function very sensitive to electric field, the decrease of the electric field by 0.5 times means that the breakdown voltage increases at least twice. In this sense, to obtain the breakdown voltage having higher fieldring, it is important to make as deep as possible, although the number of rings and the distance are of importance.

\subsection{Characteristics of trench field-ring structure}

The conventional field-ring structure having no use of trench process can't make limitless depth via diffusion time. Therefore, this study proposes a new method that the depth of junction increases through the trench etching process. Fig. 10(a) and Fig. 10(b) show cross-sectional views of the conventional field-ring structure and the trench etching

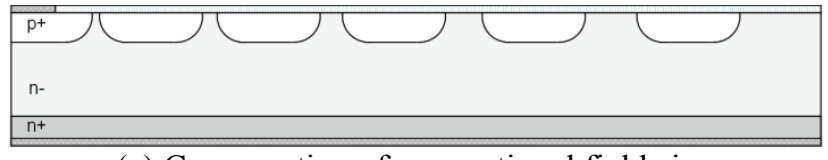

(a) Cross section of conventional field-ring

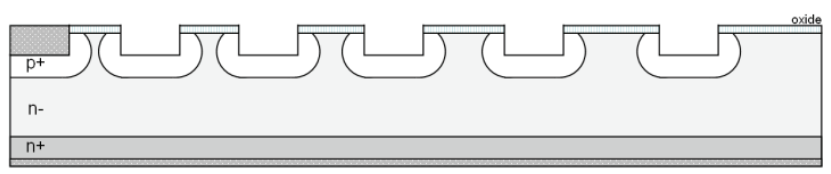

(b) Cross section trench field-ring

Fig. 10. Cross sections of the conventional field-ring structure and trench field-ring structure

process proposed herein, respectively. In this regard, whereas the conventional structure of Fig. 10(a) is to control junction depth through diffusion time, the proposed trench field-ring structure of Fig. 10(b) adopts a method of trench etching to the depth as intended prior to ion implant, capable of regulating the depth of junction different with the diffusion process.

\subsection{Simulation and analysis of trench-field ring structure}

In a trench etching process for producing a trench in $1800 \mathrm{~V}$ class of power semiconductor device, the field-rings depending on various trench etching depth were designed with the use of simulator and analyzed. Based on the design result, the relationship between breakdown voltage depending on the depth of trench and the depth at the point in which the critical field occurs is shown in Fig. 11. As expected, the breakdown voltage depending on the depth of trench has been greatly improved. In contrast with the conventional field-ring structure where the optimized breakdown voltage value was about $1725 \mathrm{~V}$, the value of breakdown voltage in the structure having about $5 \mu \mathrm{m}$ of trench etching is found to be $2244 \mathrm{~V}$, which is increased by $30 \%$. It is also found that the deeper the depth of trench

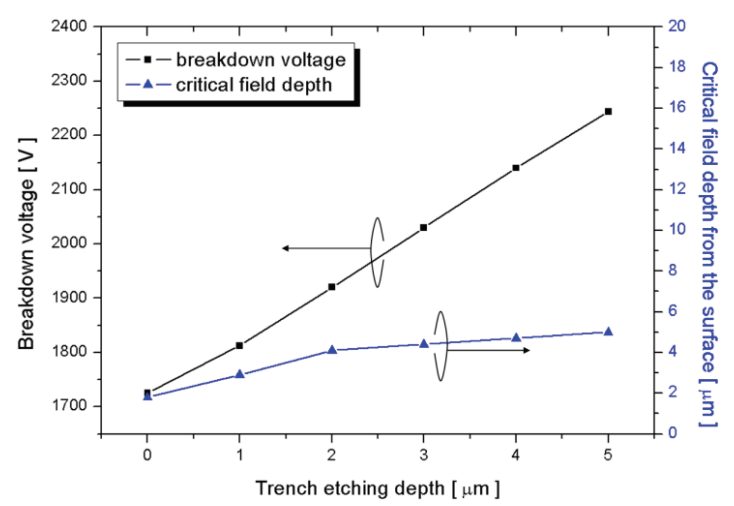

Fig. 11. According to trench etching depth, breakdown voltage subject to trench etching depth and variation of the depth to the location in which the critical field occurs from the surface 


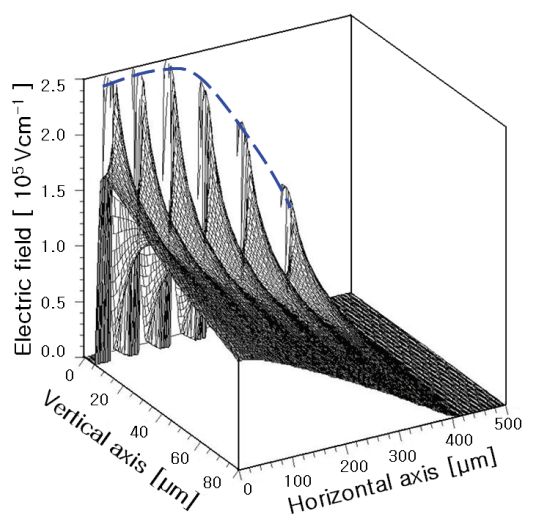

Fig. 12. Distribution of the electric field around the conventional field-ring surface

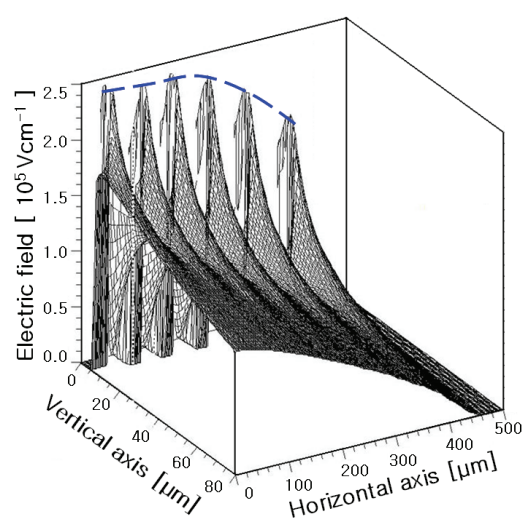

Fig. 13. Distribution of the electric field around the fieldring surface having $3 \mu \mathrm{m}$ trench etching

etching, the location of the critical field is more apart from the surface. While the location of the critical field as for the conventional structure occurs at the point about $1.8 \mu \mathrm{m}$ apart from the surface, the proposed trench-field ring structure shows that the critical field is detected at least $4 \mu \mathrm{m}$ apart from the surface. Provided the breakdown phenomenon takes place nearer to the surface, it may cause electric charge in the silicon oxide layer accordingly degenerated the voltage supporting capability. Therefore, if it is possible for the location in which breakdown occurs to be more apart from the surface, the reliability can be surely improved.

To investigate causes of increasing breakdown voltage in detail, the distributions of electric field at the time when the breakdown occurs are represented in Figs. 12, 13 and 14 .

As the field-ring structure is positioned in a left/right symmetrical fashion based on the active region, understanding the overall characteristics is possible only if the electric field intensified in the one edge of the ring junction is taken into account. Figs. 12, 13 and 14 show the 3dimensional distribution of the electric field near the surface in three cases of the conventional field-ring, fieldring to which $3 \mu \mathrm{m}$ trench etching was made, and field-ring to which $5 \mu \mathrm{m}$ trench etching was made, respectively. As

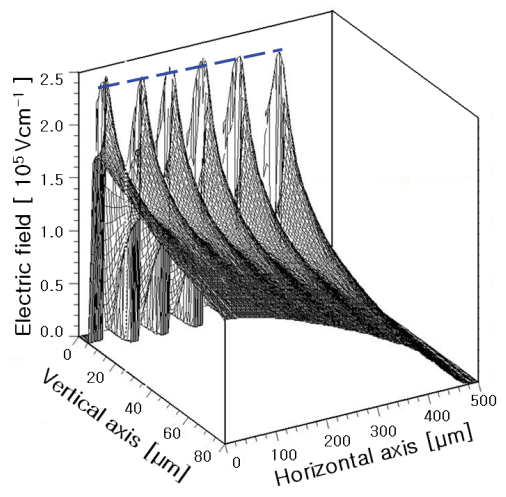

Fig. 14. Distribution of the electric field around the fieldring surface having $5 \mu \mathrm{m}$ trench etching

for the first conventional field-ring structure, the 1st, 2nd and 3 rd rings arrive at the critical electric field, while the 4 th, 5 th and 6 th rings play not so big role as the voltage divider, In other words, since the local part of the field-ring structure nearer to the main junction first arrives at the critical electric field, the breakdown phenomenon occurs prior to arriving at the max breakdown voltage allowable by this structure. Fig. 13 shows the structure to which $3 \mu \mathrm{m}$ trench etching is applied by using trench etching process, where the value of critical electric field as a whole is lower and the electric field is uniformly distributed to all rings when compared with the conventional field-ring result. At last, Fig. 14 shows the structure to which $5 \mu \mathrm{m}$ trench etching is applied by using trench etching process, where it is found that the electric field is almost uniformly distributed to all rings. The value of critical electric field is remarkably lower when compared with the conventional field-ring structure, and all field-rings have the similar electrical field and exhibit the stable operation. This eventually demonstrates that the trench field-ring structure provides greater breakdown voltage due to operation as an optimal voltage divider [20].

\section{Conclusion}

In this study, together with the description as per the mathematical modeling compared with the conventional field-ring structure, the design of the field-ring through the DOE was presented. Moreover, resulting from the simulation based on the above result, six parameters in view of the optimized field-ring structure were determined.

In addition, the improved trench field-ring structure through the trench etching process was proposed. In an attempt to identify the improved degree in comparison with the conventional field-ring structure, trench field-ring structures having different etching depths, as well as the conventional field-ring structure, were designed, and the characteristics of voltage and electric field in the trench field-ring structure were analyzed via the simulation. As a result of conducting simulations by gradually increasing 
the depth of trench etching, the breakdown voltage in the case of the field-ring having $5 \mu \mathrm{m}$ trench etching exhibited increase by about $30 \%$ than the conventional one. Looking into the result of 3-dimensional simulation was also found that the trench field-ring structure supports voltage in larger area than the conventional structure.

However, stable etching technology should be developed to realize the improved withstand voltage and reliability in view of the trench field-ring. If the field-ring structure is created non-symmetrically or bump is generated in the lateral wall due to error in the etching process, there exists a possibility for the electric field distribution to become non-uniform caused by the variation of distance between ring junctions or the variation of junction curvature. If the distribution of the electric field is not uniform, it may lead to the deterioration in the effect of increasing the junction depth through etching, resulting in sharp decline in terms of the characteristic having high breakdown voltage. Therefore, to make design manufacture as intended, the conditions of etching process enabling the profile required by the design to be realized must be obtained.

\section{Acknowledgements}

This research was supported by the MKE(The Ministry of Knowledge Economy), Korea, under IT/SW Creative research program supervised by the NIPA(National IT Industry Promotion Agency)" (NIPA-H0502-13-1105)

\section{References}

[1] Gourab Majumdar, Tadaharu Minato, "Recent and future IGBT evolution", Power Conversion Conference proceedings, pp. 355-359, 2007.

[2] B. J. Baliga, "Power semiconductor devices", PWS Publishing Company, 1996.

[3] B. Q. Tang, Y. M. Gao, J. S. Luo "The quasi-threedimensional optimum analysis of breakdown voltage of floating field-limiting rings", Solid-Stage Electronics, Vol. 41, No. 11, pp. 1821-1824, 1997.

[4] S. M. Sze, G. Gibbons, "Effect of junction curvature on breakdown voltage in semiconductors", SolidState Electronics, Vol. 9, pp. 831-845, 1966.

[5] S. M. Sze, Kwok. K. Ng, "Physics of semiconductor devices", John Wiley \& Sons, 2007.

[6] A. G. Chynoweth, "ionization rates for electrons and holes in silicon", Physical Review, Vol. 109, No. 5, pp. 1537-1540, 1958

[7] David C. Sheridan, GuofuNiu, J. Neil Merrett, John D. Cressler, Charles Ellis, Chin-Che Tin, "Design and fabrication of planar guard ring termination for highvoltage $\mathrm{SiC}$ diodes", Solid-State Electronics, 44, pp. 1367-1372, 2000

[8] G. Charitat et al., "A new junction termination tech- nique for power device : RESURF LDMOS with SIPOS layer", ISPSD'92 Proceedings, pp. 213-216, 1992

[9] J. A. Appels, et al, "Thin layer high-voltage devices (RESURF devices)", philips J. Res., Vol. 35, pp. 1-13, 1980

[10] D Jaume, et al., "High voltage planar devices using field plate and semi-resistive layers", IEEE Trans. Electron Devices, Vol. 38, No. 7, pp. 1681-1684, 1991

[11] T. Matsushita, T. Mihara, H. Yamoto, H. Hayashi, M. Okayama, Y. kawana, "Semi-insulating polycrystalline silicon(SIPOS) passivation technology", Jap J. Appl. Phys. Suppl., Vol. 15, pp. 35-40, 1976

[12] S. Colak, et al., "Lateral DMOS power transistor design", IEEE Electron Device Letters. Vol. EDL_1, pp. 51-53, 1980

[13] A. W. Ludikhuize, "A versatile 700-1200V IC process for analog and switching applications", IEEE Trans. Electron Devices, Vol. 38, pp. 1582-1589, 1991

[14] Jin He, Mansun Chan, Xing Zhang, Yangyuan Wang, "A new analytic method to design multiple floating field limiting rings of power devices", Solid-State Electronics 50, pp. 1375-1381, 2006

[15] Dong-Gun Bae, Sang-Koo Chung, "An analytic model of planar junctions with multiple floating field limiting rings", Solid-State Electronics Vol. 42, No. 3, pp. 349-354, 1998

[16] Chyn-Yen Chang, C. T. Sune, "An analytic approach for optimal field ring spacing of a diode under punchthrough operation", Electron Device Letters, Vol. EDL_7, No. 1, pp. 35-37, 1986

[17] V. Boisson, M. Le Helley, and J. P. Chante, "Analytical expression for the potential of guard rings of diodes operating in the punchthrough mode", IEEE Transactions on Electron Devices, Vol. ED_32, No. 4, pp. 838-840, 1985

[18] Jin He, Ru Huang, Xing Zhang, Yang Yuan Wang, X.B. Chen, "Analytical model of three-dimensional effect on voltage and edge peak field distributions and optimal space for planar junction with a single field limiting ring", Solid-State Electronics 45, pp.7985, 2001

[19] Han Sin Lee, Yo Han Kim, Ey Goo Kang and Man Young Sung, "Design and Analysis of $\mathrm{SiO} 2 / \mathrm{P}+$ Collector IGBT Applicable to 1700 V High Voltage", ICSE'06 Proceedings, pp. 489-492, 2006

[20] K. R. Davis, R. D. Schrimpf, F. E. Cellier, and K. F. Galloway, "The effect of ionizing radiation on powerMOSFET termination structures", IEEE transaction on nuclear science, Vol. 36. No. 6, pp. 2104-2109, 1989

[21] Yo Han Kim, Han Sin Lee, Young Mok Kim, Sin su Kyung, Ey Goo Kang, Man Young Sung, "A New Edge Termination Technique to Improve Voltage Blocking Capability and Reliability of Field Limiting Rings for Power Devices", ICICDT'08 Proceedings, pp. 71-74, 2008 


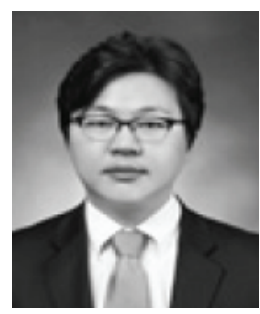

Eun Sik Jung He received Ph.D. in Electrical Engineering from Korea University. His research interests include readout integrated circuit for uncooled IR detector and high-voltage power devices. Now, He is the chief executive officer in MapleSemi Co.

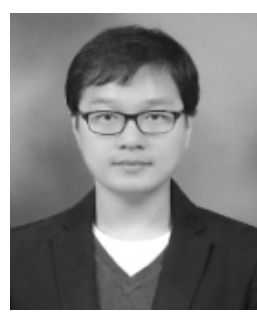

Sinsu Kyoung He received the B.S. and M.S. degree in Electrical Engineering from Korea University, in 2006 and 2009. He is the head of research center in Power Cube Semiconductor Co. Especially, he is interested in Power semiconductor device and silicon carbide device.

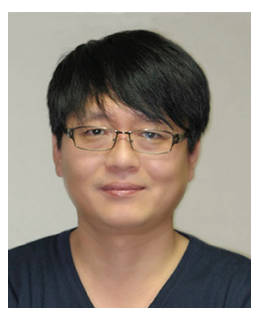

Hunsuk Chung He received M.S and Ph.D. degree in Computer Science Engineering from Hongik University. He is currently the professor in dept. of photovoltaic Engineering at Far East University. His research interests are Smart Grid and Smart Devices.

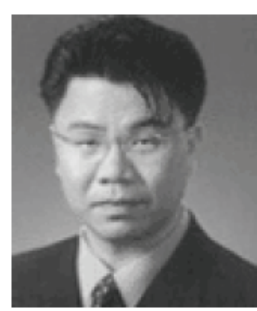

Ey Goo Kang He received M.S and Ph.D. degree in Electrical Engineering from Korea University. He is currently the professor in dept. of photovoltaic Engineering at Far East University. His research interests are Smart Power Devices and Power IC. 